\title{
Two highly efficient accumulation models of large gas fields in China
}

\author{
Wang Hongjun ${ }^{1 *}$, Bian Congsheng${ }^{1}$, Liu Guangdi², Sun Mingliang² and Li \\ Yongxin ${ }^{1}$
}

${ }^{1}$ Research Institute of Petroleum Exploration \& Development, CNPC, Beijing 100083, China

${ }^{2}$ China University of Petroleum, Beijing 102249, China

(C) China University of Petroleum (Beijing) and Springer-Verlag Berlin Heidelberg 2014

\begin{abstract}
Based on reserve abundance, large gas fields in China can be divided into two types: type one of high abundance large gas fields, dominated by structural gas reservoirs; type two of low abundance large gas fields, dominated by stratigraphic and lithologic gas reservoirs. The formation of these two types of large gas fields is related to the highly efficient accumulation of natural gas. The accumulation of high abundance gas fields is dependent on the rapid maturation of the source kitchen and huge residual pressure difference between the gas source kitchen and reservoir, which is the strong driving force for natural gas migration to traps. Whereas the accumulation of low abundance gas fields is more complicated, involving both volume flow charge during the burial stage and diffusion flow charge during the uplift stage, which results in large area accumulation and preservation of natural gas in low porosity and low permeability reservoirs. This conclusion should assist gas exploration in different geological settings.
\end{abstract}

Key words: Natural gas, gas source kitchen, highly efficient accumulation, large gas field, reserve abundance, resource potential

\section{Background}

In the last decade, natural gas exploration and development in Chinese onshore basins has accelerated. Annual increased proven reserves are above 500 billion cubic meters $(\mathrm{bcm})$ from 2003, and annual natural gas production has increased from $50 \mathrm{bcm}$ in 2000 to nearly $100 \mathrm{bcm}$ in 2011 (Dai, 2009; Dai et al, 2010). The rapid development of the natural gas industry takes advantage of the discovery of a batch of large gas fields with proven gas reserves of hundreds of billions of cubic meters, which are mainly distributed in three large-scale superimposed basins in middle-western China, i.e. the Tarim, Ordos and Sichuan Basins (Fig. 1 and Fig. 2). Paleozoic marine-facies cratonic basins were overlapped by Mesozoic and Cenozoic continental facies foreland \& intra-continental depression basins forming the Chinese superimposed basins, where primary gas sources are oil-cracked gas of marine facies basins (Zhao et al, 2007) and coal-formed gas from continental facies (including marine to continental transitional facies). Chinese scholars, represented by Academician Dai Jinxing, have undertaken long-term research on formation of large Chinese gas fields (Dai, 2003; Zhang and Zhu, 2008). They proposed that the formation and distribution of large-medium scale gas fields were controlled by a gas-generating center (with a gas-generating intensity

*Corresponding author. email: whj@petrochina.com.cn

Received December 11, 2012 over 2 billion $\mathrm{m}^{3} / \mathrm{km}^{2}$ ) and its periphery. Favorable conditions and accumulation characteristics for forming medium-large gas fields include: regional caprocks, high-quality reservoirs, large-scale paleo-uplifts, traps in the deposition center of new tectonic movement, accumulation in low energy potential areas, and late-stage accumulation, which answer the common issues with natural gas accumulation in Chinese basin environments and effectively guide the exploration for large gas fields.

With the increasing number of discovered large gas fields, Chinese large gas fields can be distinctly divided into three types (Zhao and Liu, 2008) (Table 1): type one is the large gas fields with high reserve abundance, where recoverable reserve abundance is greater than 800 million $\mathrm{m}^{3} / \mathrm{km}^{2}$; type two is the large gas fields with low abundance, where recoverable reserve abundance is less than 250 million $\mathrm{m}^{3} / \mathrm{km}^{2}$; and type three is the large gas fields with reserve abundance between type one and type two. From Table 1 we can see the former two types of large gas fields make up the majority.

Large gas fields with high abundance are dominated by large-scale structural gas reservoirs and structural-lithologic gas reservoirs, where the reservoir physical properties are favorable, with porosity commonly greater than $10 \%$, permeability greater than $1 \mathrm{mD}$, and well-sorted sandstone reservoirs or carbonate reef flat reservoirs which are thick and continuous in distribution (Zhao et al, 2007), and the gas column height can reach hundreds of meters. These gas reservoirs usually have distinct gas-water contact and are 
mostly abnormally high-pressure gas reservoirs. The gasbearing area of individual gas reservoirs is limited (dozens to hundreds of $\mathrm{km}^{2}$ ), whereas its controlled reserves scale is quite large (hundreds of billions of $\mathrm{m}^{3}$ ) and the reserve abundance is high, such as the Kela 2 gas field in the Tarim Basin and the Puguang gas field in the Sichuan Basin (Fig. 2).
Large gas fields with low abundance consist of clusters of multiple small-scale lithologic gas reservoirs and are distributed extensively in the Ordos and Sichuan Basins. The gas-bearing area of the whole gas field is large (thousands to tens of thousands of $\mathrm{km}^{2}$ ) and the reserves scale is large (hundreds of billions to trillions of $\mathrm{m}^{3}$ ) as well, whereas the

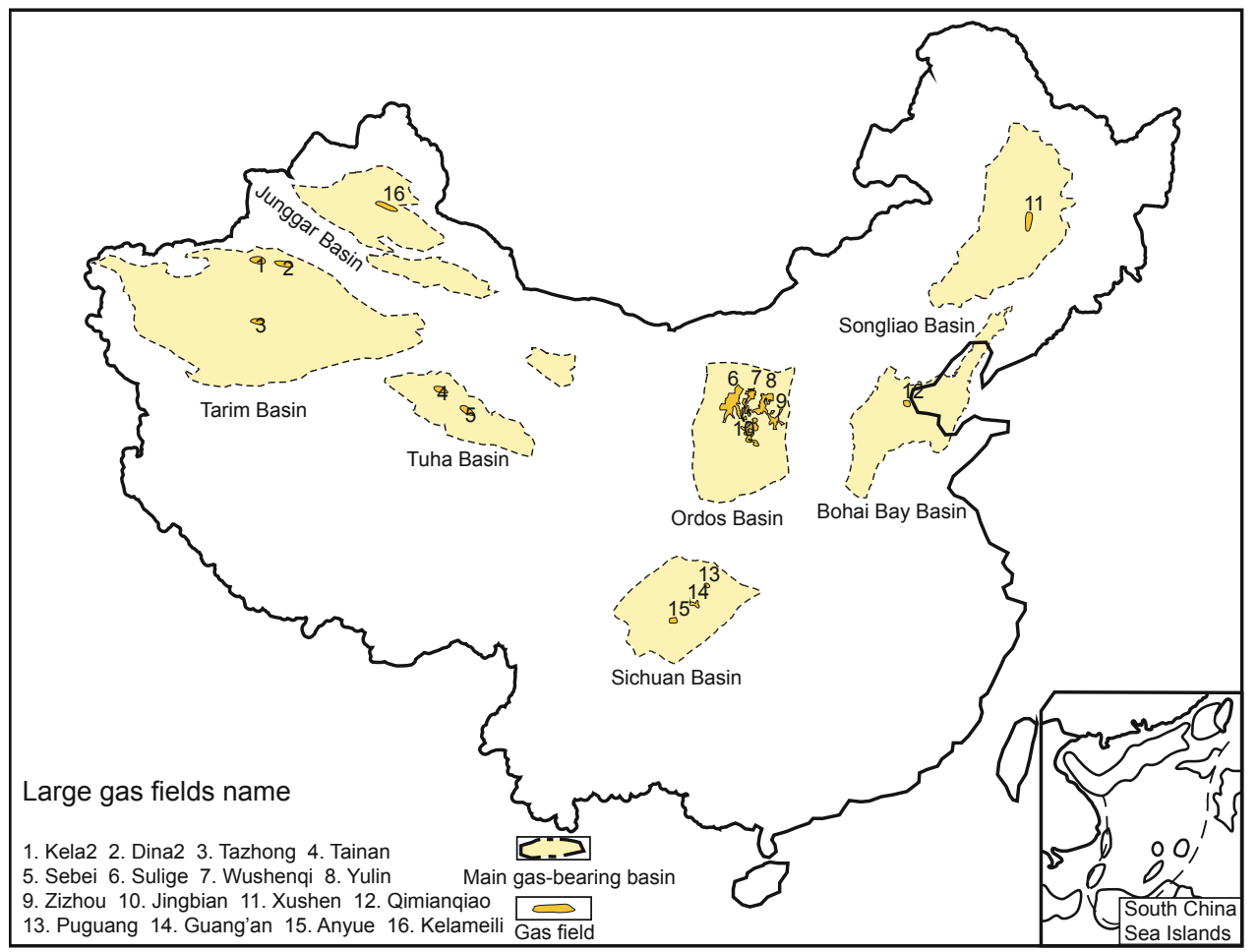

Fig. 1 Distribution of large gas fields in Chinese onshore basins

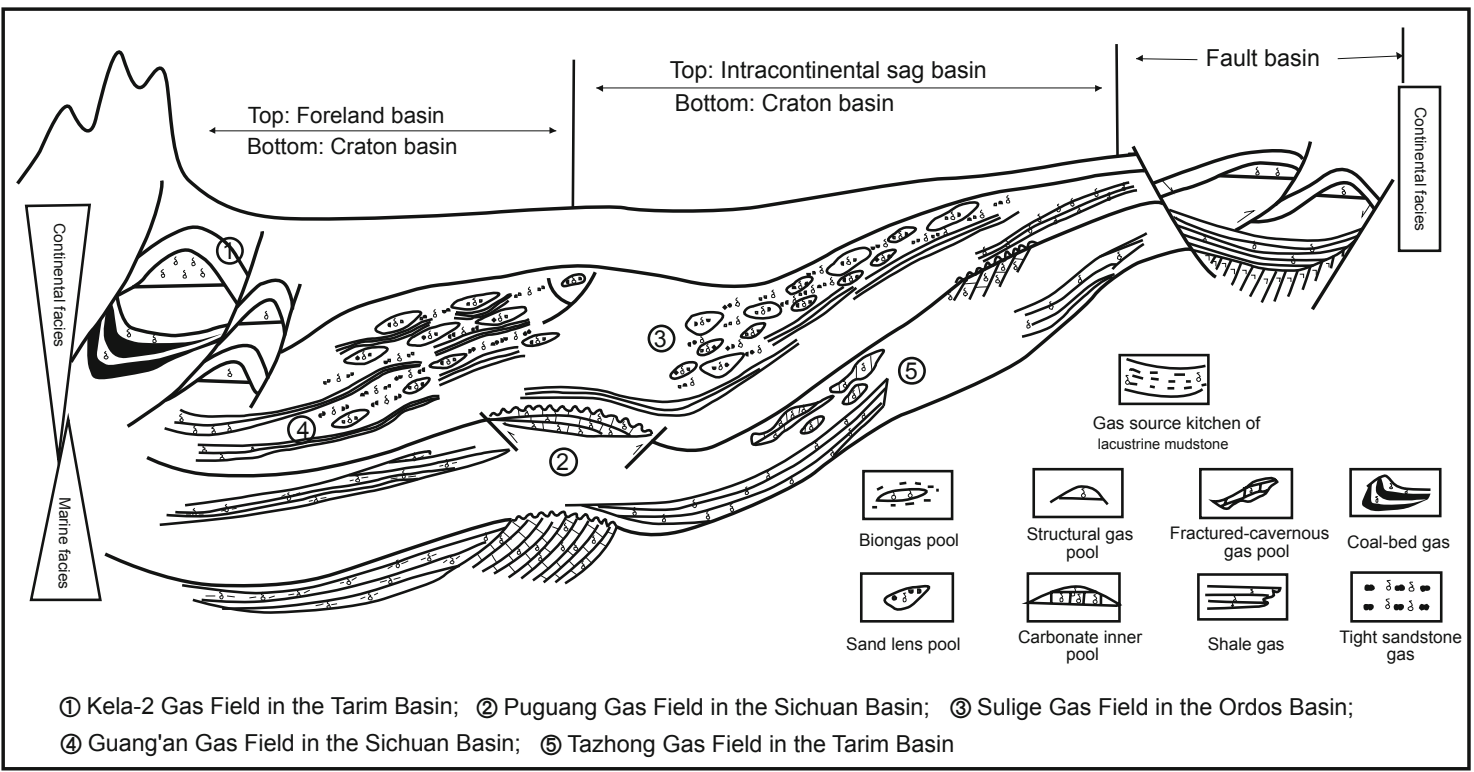

Fig. 2 Distribution mode of large gas fields in Chinese basins

reserve abundance is low. A large gas field usually consists of thousands of lithologic gas reservoirs with small individual scale and presents a gas reservoir group as a whole (Zhao et al, 2013). Taking the Sulige gas field in the Ordos Basin as an example, the proven gas reserves are 1,101 billion $\mathrm{m}^{3}$ and the gas-bearing area is nearly $7,980 \mathrm{~km}^{2}$, among which about 50-80 thousand individual gas reservoirs with gas column height of 2-6 $\mathrm{m}$ can be divided by clear sand body shape. The physical properties of the reservoirs are poor as a whole (Fig. 3 ). Both conventional sandstone reservoirs with porosity over 
Table 1 Statistics of geological parameter characteristics for large gas fields in China

\begin{tabular}{|c|c|c|c|c|c|c|c|c|c|c|c|c|c|c|}
\hline \multirow{2}{*}{ No. } & \multirow{2}{*}{$\begin{array}{l}\text { Gas field } \\
\text { name }\end{array}$} & \multirow{2}{*}{ Basin } & \multirow{2}{*}{$\begin{array}{r}\text { Area, } \\
\mathrm{km}^{2}\end{array}$} & \multirow{2}{*}{ Trap type } & \multirow{2}{*}{$\begin{array}{l}\text { Gas in place, } \\
\text { billion } \mathrm{m}^{3}\end{array}$} & \multirow{2}{*}{$\begin{array}{c}\text { Technical } \\
\text { recoverable } \\
\text { reserves, billion } \mathrm{m}^{3}\end{array}$} & \multirow{2}{*}{$\begin{array}{l}\text { Reserve abundance, } \\
\times 10^{2} \text { million } \mathrm{m}^{3} / \mathrm{km}^{2}\end{array}$} & \multirow{2}{*}{$\begin{array}{l}\text { Reserve } \\
\text { abundance } \\
\text { type }\end{array}$} & \multirow{2}{*}{ Age } & \multicolumn{3}{|c|}{ Reservoir characteristics } & \multirow{2}{*}{$\begin{array}{c}\text { Natural } \\
\text { gas origin }\end{array}$} & \multirow{2}{*}{$\begin{array}{l}\text { Gas reservoir } \\
\text { forming phase }\end{array}$} \\
\hline & & & & & & & & & & Lithology & Porosity, $\%$ & $\begin{array}{c}\text { Permeability, } \\
\mathrm{mD}\end{array}$ & & \\
\hline 1 & Puguang & Sichuan & 126 & $\begin{array}{l}\text { Structural- } \\
\text { lithologic }\end{array}$ & 412 & 291 & 23 & High & $\mathrm{T}_{1}$ & Dolomite & $6-8$ & $0.1-3000$ & $\begin{array}{l}\text { Oil cracked } \\
\text { gas }\end{array}$ & $\mathrm{K}-\mathrm{N}$ \\
\hline 2 & Kela 2 & Tarim & 48 & Structural & 284 & 213 & 44.3 & High & $\mathrm{K}, \mathrm{E}$ & Sandstone & $9-14$ & $4.0-350$ & & N-Q \\
\hline 3 & Dina 2 & Tarim & 125 & Structural & 175 & 114 & 9.1 & High & $\mathrm{N}$ & Sandstone & $8-15.2$ & $0.5-216$ & & N-Q \\
\hline 4 & Sulige & Ordos & 7980 & Lithologic & 1101 & 566 & 0.7 & Low & $P$ & Sandstone & $7-11$ & $0.01-10$ & & $\mathrm{~K}-\mathrm{N}$ \\
\hline 5 & Daniudi & Ordos & 1546 & Lithologic & 393 & 188 & 1.2 & Low & C-P & Sandstone & $5-11$ & $0.001-10$ & & $\mathrm{~K}-\mathrm{N}$ \\
\hline 6 & Yulin & Ordos & 1716 & Lithologic & 181 & 124 & 0.7 & Low & C-P & Sandstone & $5-11$ & $0.01-10$ & & $\mathrm{~K}-\mathrm{N}$ \\
\hline 7 & Zizhou & Ordos & 1189 & Lithologic & 115 & 68 & 0.6 & Low & C-P & Sandstone & $4-9$ & $0.01-10$ & $\begin{array}{l}\text { Coal-formed } \\
\text { gas }\end{array}$ & $\mathrm{K}-\mathrm{N}$ \\
\hline 8 & Wushenqi & Ordos & 872 & Lithologic & 101 & 52 & 0.6 & Low & C-P & Sandstone & $3.5-14$ & $0.01-10$ & & $\mathrm{~K}-\mathrm{N}$ \\
\hline 9 & Shenmu & Ordos & 828 & Lithologic & 101 & 52 & 0.6 & Low & C-P & Sandstone & $4-12$ & $0.01-10$ & & $\mathrm{~K}-\mathrm{N}$ \\
\hline 10 & Guang'an & Sichuan & 579 & $\begin{array}{l}\text { Structural- } \\
\text { lithologic }\end{array}$ & 136 & 61 & 1.1 & Low & $\mathrm{T}_{3}$ & Sandstone & $6-13$ & $0.001-10$ & & $\mathrm{~K}-\mathrm{N}$ \\
\hline 11 & Anyue & Sichuan & 361 & Lithologic & 117 & 53 & 1.5 & Low & $\mathrm{T}_{3}$ & Sandstone & $6-14$ & $0.001-14$ & & $\mathrm{~K}-\mathrm{N}$ \\
\hline 12 & Hechuan & Sichuan & 1058 & $\begin{array}{l}\text { Lithologic- } \\
\text { structural }\end{array}$ & 230 & 103 & 1 & Low & $\mathrm{T}_{3}$ & Sandstone & $7-10$ & $0.001-50$ & & K-N \\
\hline 13 & Tazhong & Tarim & 742 & $\begin{array}{l}\text { Structural- } \\
\text { lithologic }\end{array}$ & 353 & 216 & 2.9 & Medium & $\mathrm{O}$ & Carbonate & $3-6$ & $3.5-12$ & $\begin{array}{l}\text { Oil cracked } \\
\text { gas }\end{array}$ & E-Q \\
\hline
\end{tabular}

$10 \%$ and permeability of $0.01-10 \mathrm{mD}$ and unconventional tight sandstone reservoirs with porosity less than $10 \%$ and permeability less than $1 \mathrm{mD}$ are included, and the reservoir heterogeneity is strong (Zhang et al, 2009). This type of large gas field is mostly formed in gentle structural areas above large-scale cratonic basins.

These two types of large gas fields are quite different in both feature and structure, which implies they are different in thermal evolution of gas source rocks and charging accumulation processes (Law, 2002; Zhao et al, 2005a; 2005 ; 2005c). Thus, this paper mainly studies the controlling factors of the evolution process of gas source kitchen and the charging accumulation process of natural gas on the formation of large gas fields, in the hope of revealing the highly efficient accumulation process of natural gas under different geological conditions.

\section{Highly efficient accumulation of large gas fields}

\subsection{Favorable gas accumulation conditions}

This paper takes a foreland basin as an example to investigate the highly efficient accumulation of high abundance large gas fields. The Kela 2 gas field, a typical high abundance gas field, is situated on the second-row thrust fault anticlinal belt in the north wing of the Kuqa Depression, Tarim Basin (Zhao et al, 2005b; 2006) (Fig. 4). The area of trap at the top of the Paleogene of the Kela 2 structure is 48.1 $\mathrm{km}^{2}$, the closure height is $455 \mathrm{~m}$, and it is an anticline with a long axis. The gas field has a proven gas reserve of 284 billion $\mathrm{m}^{3}$, and gas layer thickness of up to $448 \mathrm{~m}$, with gas filling the trap fully.

Mesozoic and Cenozoic deposition in the Kuqa Depression includes the entire depositional sequence from

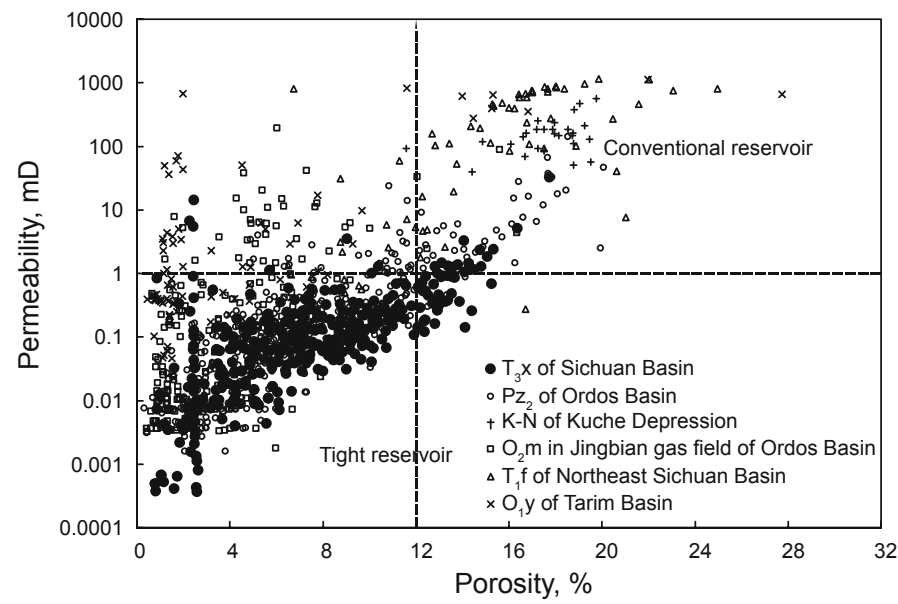

Fig. 3 Reservoir physical property parameters of Chinese large gas fields

Triassic-Quaternary system, among which the Middle Upper Triassic-Middle Lower Jurassic series are the humid climate limnetic facies coal series which are proven effective gas source rocks. The Cretaceous deposit is a proluvialfluvial facies dominated sedimentary assemblage formed in relatively blocked and dry environment and is a set of strata dominated by reservoir rock development. The Paleogene and Neogene deposits are a blocked salty lagoonal facies sedimentary assemblage formed in a dry climate (Zhao et al, 2005b), where a quite thick gypsum member was developed, and plastic flow occurred in the later-stage deformation, affecting shallow layer structural deformation greatly. The premium coal-seam source rocks right next to high porosity high permeability clastic reservoirs, plus gypsum rock with excellent seal ability constitute a very promising sourcereservoir-cap combination, laying a solid material foundation for gas accumulation.

Rapid late stage subsidence is a typical characteristic of 

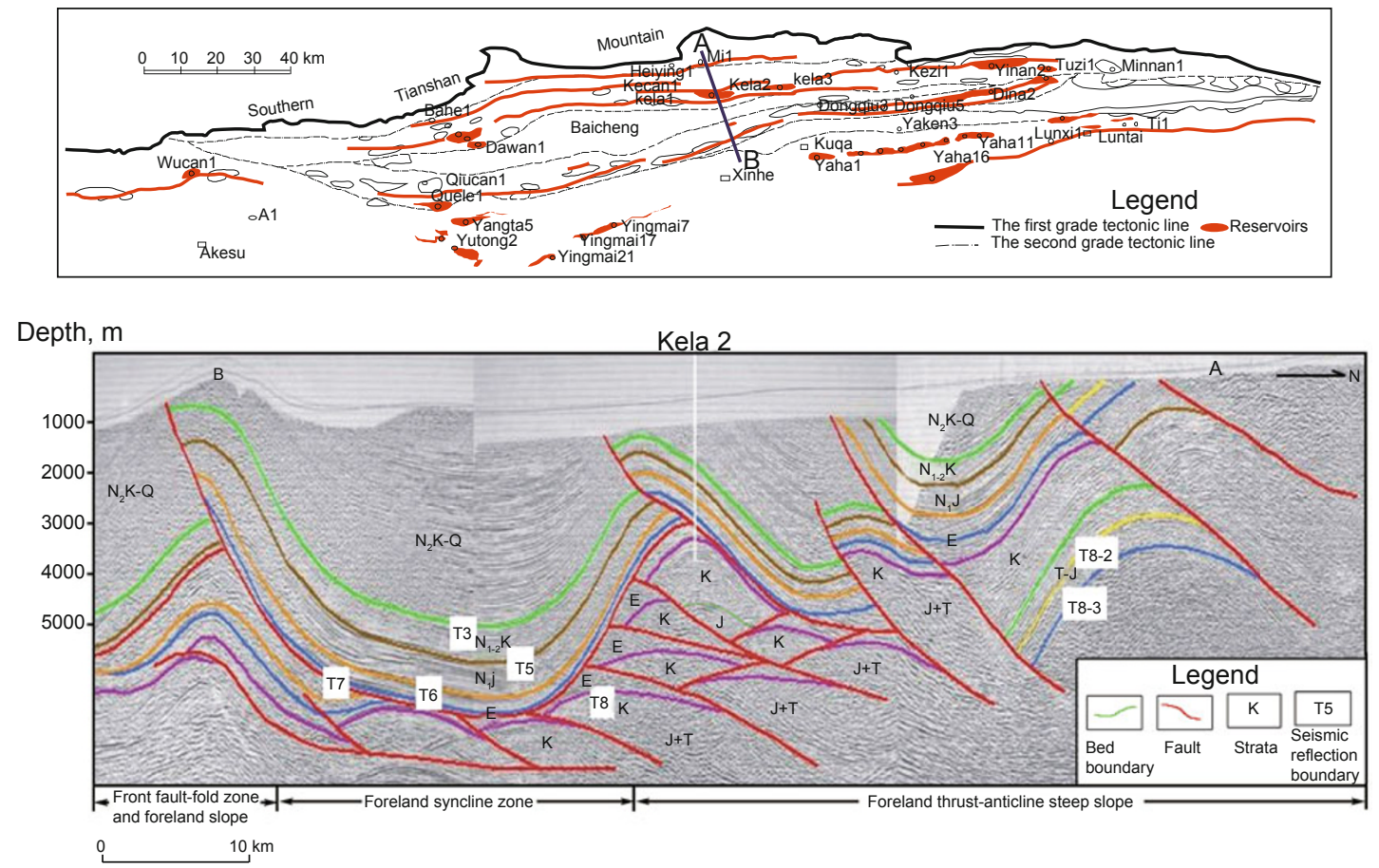

Fig. 4 Structural unit division and hydrocarbon reservoir distribution in the Kuqa Depression (Zhao et al, 2005b; 2006)

strata filling in the Kuqa Depression since the Neogene (Zhao et al, 2005b) (Fig. 5). By the end of the Paleogene, affected by the collision between the Indian plate and the Qinghai-Tibet plate, the northern Tarim Basin underwent intracontinental subduction underneath the Tianshan orogenic belt. The Tianshan Mountain uplifted rapidly and the Kuqa Depression was formed at the mountain front, and continental-facies red sedimentary formation with a thickness of 6,000 m was deposited since Cretaceous due to rapid deposition in a dry environment. In the center of the depression, the MesoCenozoic sedimentary thickness was over $11,000 \mathrm{~m}$ and that of the Neogene was up to $4,500 \mathrm{~m}$, among which, the sedimentary thickness of the Pliocene Kuqa Formation exceeded 2,000 $\mathrm{m}$ and the maximum deposition rate reached $1,300 \mathrm{~m} / \mathrm{Ma}$. The deposition rates in various stages of the Mesozoic were lower, commonly varying from $20 \mathrm{~m} / \mathrm{Ma}$ to $40 \mathrm{~m} / \mathrm{Ma}$ (Zhao et al, 2005b) (Table 2).

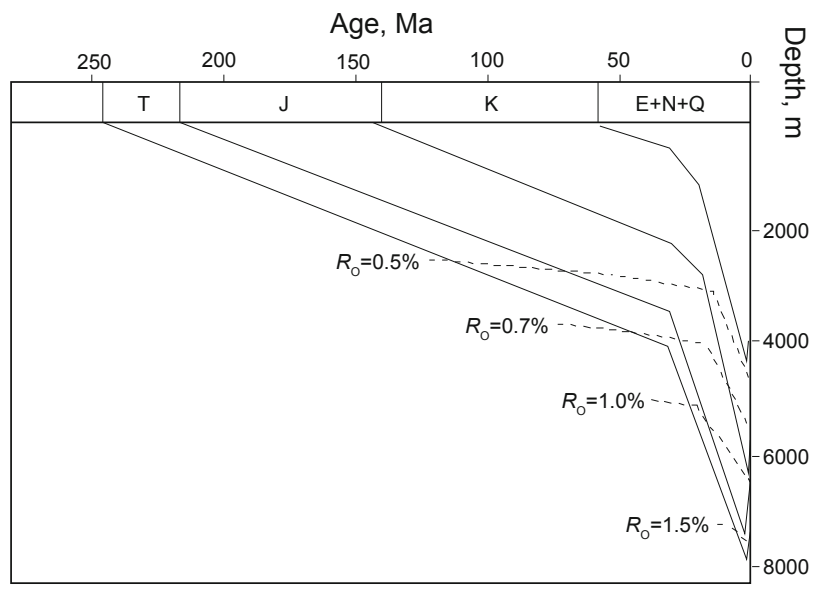

Fig. 5 Burial history of the Kela 2 gas reservoir (Zhao et al, 2005b)
Table 2 Deposition rate in the Kuqa Depression (Zhao et al, 2005b)

\begin{tabular}{ccccc}
\hline \multicolumn{2}{c}{ Geologic age } & $\begin{array}{c}\text { Stratum } \\
\text { thickness, } \mathrm{m}\end{array}$ & Duration, Ma & $\begin{array}{c}\text { Deposition } \\
\text { rate, } \mathrm{m} / \mathrm{Ma}\end{array}$ \\
\hline \multirow{2}{*}{ Cenozoic } & Neogene & 4500 & $19(24-5)$ & 240 \\
& Paleogene & 750 & $41(65-24)$ & 18 \\
\hline \multirow{2}{*}{ Mesozoic } & $\begin{array}{c}\text { Early } \\
\text { Cretaceous }\end{array}$ & 1340 & $39(135-96)$ & 34 \\
& Jurassic & 2500 & $73(208-135)$ & 34 \\
& Triassic & 3300 & $42(250-208)$ & 78 \\
\hline
\end{tabular}

Rapid late-stage subsidence in the Kuqa Depression since the late Cretaceous is another favorable condition for highly efficient gas accumulation, which may be reflected in two aspects: one is that Jurassic coal series source rocks have large total gas generating volume and have experienced a rapid gas-generating process under the effect of rapid laterstage burial, which could have led to highly efficient gas accumulation; the other is that the huge residual pressure difference generated between the gas source kitchen and the reservoir during rapid gas generation served as the strong driving force for natural gas migration to traps (Muggeridge et al, 2005; Xu et al, 2010; Zhao et al, 2005d; Liu et al, 2008).

\subsection{Reservoir forming process and major controlling factors}

\subsubsection{Highly efficient gas kitchen generation process}

The distribution area of coal series source rocks from Triassic to Jurassic in the Kuqa Depression ranges from $12,000 \mathrm{~km}^{2}$ to $14,000 \mathrm{~km}^{2}$, with the maximum total thickness of about $1,000 \mathrm{~m}$. Organic macerals are dominated by vitrinite (mostly more than $60 \%$ ), followed by inertinite (10\%-25\%) and a little liptinite (mostly less than 10\%). 
Liptinite is dominated by exinite, with small amounts of sapropelinite, kerogen is dominated by Type III, and it is a set of gas generating-dominated source rocks. The average gasgenerating intensity of Triassic and Jurassic source rocks is above 2 billion $\mathrm{m}^{3} / \mathrm{km}^{2}$ in the main depression and the gasgenerating intensity of such source rocks is above 4 billion $\mathrm{m}^{3} / \mathrm{km}^{2}$ in the hinterland of the depression (Zhao et al, 2005a; Liang et al, 2003; Qin et al, 2007), forming a high-quality gas source kitchen. So far all the large gas fields discovered there are distributed within the high gas-generating center of this high-quality gas source kitchen.

Total gas-generating intensity shows that the gasgenerating volume of the Triassic and Jurassic rocks in the Kuqa Depression is huge, providing material support for forming medium-large scale gas fields. From the gasgenerating process of source rocks, this set of hydrocarbon source rocks still has another prominent characteristic: affected by late-stage rapid burial, the stage of generating a large amount of gas is quite short and gas supply efficiency is very high.

The geothermal gradient of the Kuqa Depression was 3.1 ${ }^{\circ} \mathrm{C} / 100 \mathrm{~m}$ in Mesozoic, and has decreased from $2.8{ }^{\circ} \mathrm{C} / 100 \mathrm{~m}$ to present $2.5^{\circ} \mathrm{C} / 100 \mathrm{~m}$ since Paleogene (Zhao et al, 2005b). In addition, the overall Cenozoic in the depression was not thick enough, therefore gas source rocks had remained at an immature stage before Neogene and $R_{\mathrm{o}}$ was less than $0.6 \%$. Over $5,000 \mathrm{~m}$ of strata has been stacked rapidly by intense subsidence of depression since Neocene (23 Ma), particularly, the strata thickness that has been accumulated since the Pliocene (5 Ma) exceeds $3,500 \mathrm{~m}$, which leads to quick burial of the source rocks below 6,000-7,000 $\mathrm{m}$ (Zhao et al, 2005b). As shown in the source rock maturity evolution curve of the Lower Jurassic top simulated with artificial points for the central Baicheng Depression, the Jurassic gas source rocks entered the oil generation threshold $\left(R_{\mathrm{o}}=0.6 \%\right)$ no later than $15 \mathrm{Ma}$ and entered the oil generation peak $\left(R_{\mathrm{o}}=1.0 \%\right)$ by 5 $\mathrm{Ma}$, and $R_{\mathrm{o}}$ reaches $2.1 \%$ at present. $R_{\mathrm{o}}$ value of the Jurassic source rocks increased from $1.0 \%$ to $2.1 \%$ and the primary gas generation process completed during a short period of 5 Ma. The Jurassic source rocks are characterized by rapid gas generation in a short period as well as a large overall gasgenerating volume, therefore it can be called highly efficient gas source kitchen (Zhao et al, 2005a). It is certain that the gas source kitchen possessed high gas supply efficiency, which is favorable for forming highly efficient gas reservoirs within its radial range. The increment $\Delta R_{\mathrm{o}}$ of Jurassic hydrocarbon source rock $R_{\mathrm{o}}(\%)$ increased over $5 \mathrm{Ma}$, can reflect the gas yield efficiency in the primary gas generation stage $\left(R_{0}=0.8 \%-2.0 \%\right)$ after the source rocks entered hydrocarbon generation threshold, which can characterize the distribution of highly efficient gas source kitchen (Zhao et al, 2005a; 2005b), and its interior and periphery areas are favorable places for discovering large gas fields with high abundance (Fig. 6).

\subsubsection{The controlling effect of pressure difference between source rocks and reservoirs}

The highly efficient gas accumulation process is also controlled by accumulation dynamics, dominant migration and conduit system, and good sealing of caprocks. There were a number of dominant migration paths from the source rocks to traps inside the thrust nappe in the formation stages of the Kela 2 gas reservoir, and the thick gypsum mudstone plays a good sealing and protecting role in gas accumulation and late-stage preservation (Liu et al, 2008). From the origin, whether a strong driving force for charging is available depends on the combined effect of various geologic stresses upon fluid in the accumulation stage. A strong tectonic movement, such as the structural deformation caused by the Cenozoic extrusion nappe structure, might generate additional force for directional and accelerated migration of subsurface fluids. Overpressure could be generated during the quick hydrocarbon generation process of the Jurassic source rocks since $5 \mathrm{Ma}$ ago, which could induce the acting force of fluid pressurization in source rocks to generate a great residual pressure difference, i.e. the difference between residual hydrocarbon supply pressure of gas source kitchen and residual pore fluid pressure of the reservoir in the critical moment of gas accumulation, that is the direct driving force for highly efficient gas migration.

Research reveals that, the abnormal formation pressure in the Kuqa Depression is jointly controlled by multiple factors such as uneven compaction, tectonic compression, fluid charging, and sealing strata performance (Liang et al, 2003; Chen et al, 2004; Zhao et al, 2006; Liu et al, 2008). Through the establishment of an overpressure equation with its origin implications, necessary parameters were acquired with the multivariate statistics method, the abnormal pressure evolution history of the Kuqa Depression was evaluated, and then the pressure evolution from the Jurassic source rock maturation stage to now was detailed. The reservoir

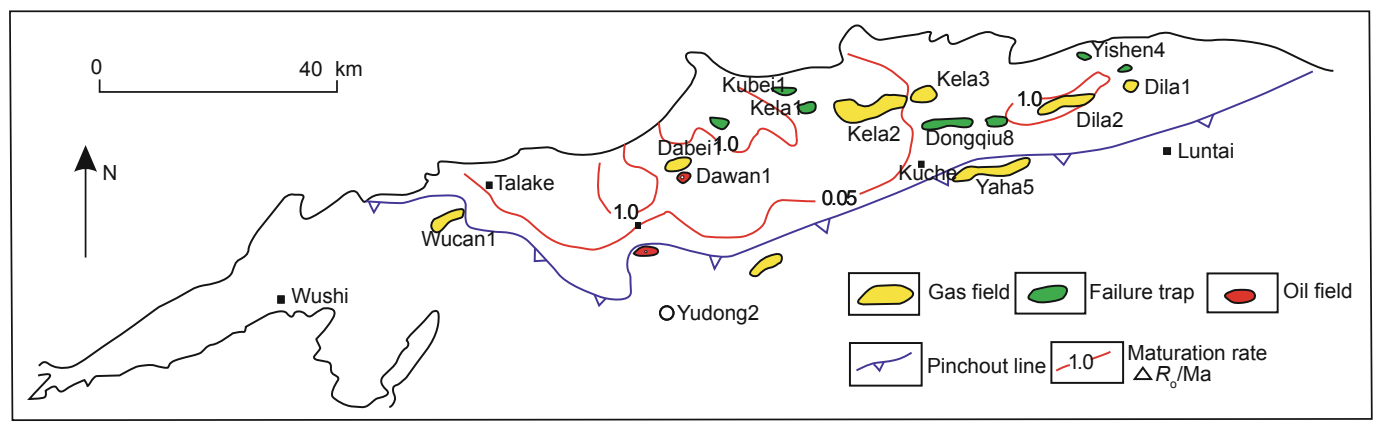

Fig. 6 Gas source rock maturation rate $\Delta R_{\mathrm{o}}(\% / \mathrm{Ma})$ isoline of the Kuqa Depression since $5 \mathrm{Ma}(>0.05$ means highly efficient gas source kitchen) (Zhao et al, 2005b) 
pressure in the accumulation stage was determined through the combination of multiple methods such as fluid inclusion analysis and under-compaction modelling, which showed that the reservoir fluid pressure was basically under normal levels during the accumulation stage of the Kela 2 gas reservoir, and its source-reservoir residual pressure difference was up to 45 $\mathrm{MPa}$ (Fig. 7), which served as the strong driving force for gas charging from source kitchens to traps. Through comparison of the average residual pressure difference and buoyancy of the Kuqa Depression in the accumulation stage of primary gas reservoirs, we can see that the average residual pressure difference gradients in the structures of various reservoirs were greater than $0.03 \mathrm{MPa} / \mathrm{m}$, whereas the buoyancy gradients were less than $0.008 \mathrm{MPa} / \mathrm{m}$. It is clear that the residual pressure difference and residual pressure gradient were higher than the buoyancy and buoyancy gradient, and the difference between the gradients could be an order of magnitude, which indicates that source-reservoir residual pressure difference is the primary driving force for highly efficient gas migration and accumulation.

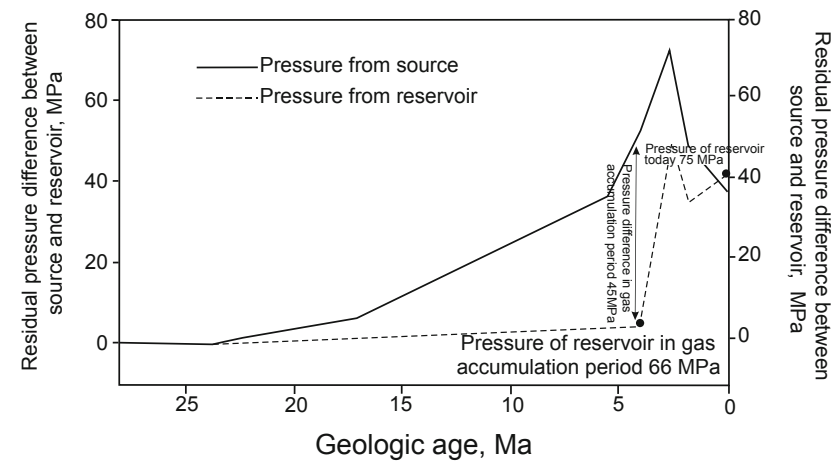

Fig. 7 Source-reservoir residual pressure difference in the Kela 2 gas field in the accumulation stage

\section{Highly efficient accumulation of low abundance large gas fields}

\subsection{Favorable reservoir forming conditions}

The Upper Paleozoic Sulige gas field in the Ordos Basin is a typical low abundance large gas field. Situated in the northwestern part of the Ordos Basin, it is the largest gas field discovered in recent years. By the end of 2010, its proven gas reserves have exceeded 1 trillion $\mathrm{m}^{3}$ and its proven gasbearing area is nearly $8,000 \mathrm{~km}^{2}$. Distributed on the gentle hinterland slope of the cratonic basin, where faults are not developed, the gas field produces gas from the 8th member of Permian Shihezi Formation and the 1st member of Shanxi Formation, and the gas layers are relatively thin, averaging at $8-20 \mathrm{~m}$. The whole gas field is a lithologic gas reservoir group that consists of tens of thousands of sand bodies with small individual scale (Figs. 8 and 9). The porosity of reservoir mainly ranges from $2 \%$ to $10 \%$, with the maximum value of $18 \%$; whereas the permeability varies from 0.01 to $0.5 \mathrm{mD}$, representing a typical low porosity and low permeability

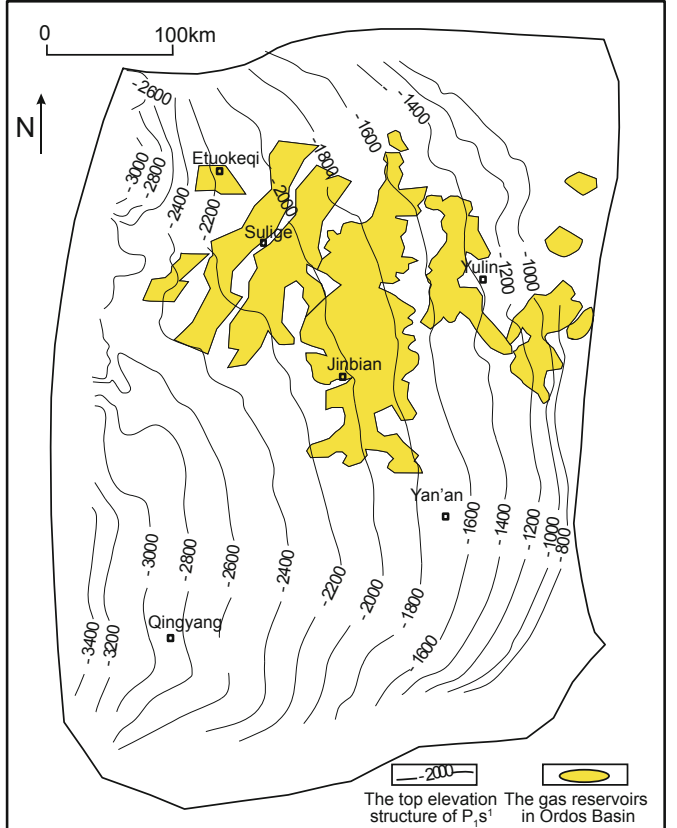

Fig. 8 Slope structure and gas reservoirs of Upper Paleozoic in the Ordos Basin

reservoir. The gas primarily comes from the coal series of the Carboniferous and Permian Taiyuan and Shanxi Formations (Shanley et al, 2004). These coal series gas source rocks are widely distributed over the whole area with a stable thickness.

The Ordos Basin is one of the important Middle Paleozoic cratonic basins in middle-western China. The Upper Paleozoic geomorphology and geology of the middle slope part are characterized by: 1) large area, the slope is about $260 \mathrm{~km}$ wide from east to west and about $500 \mathrm{~km}$ long from north to south, covering an area of about $130,000 \mathrm{~km}^{2}$, which occupies $46 \%$ of the whole basin area; 2) monotonous structural feature and gentle dip, with dips usually from $1^{\circ}$ to $2^{\circ}$ with a maximum of $3^{\circ}$, and lack of local structure (Zhao et al, 2005c).

Under this stable and gentle structural setting, the highly efficient gas accumulation process is controlled by three favorable conditions: one is that the large-area coal series source rock is in close contact with the reservoir, forming a "lower-source upper-reservoir" combination, so that natural gas accumulation benefits from near-source "planar" hydrocarbon supply (Fig. 10); the second is that tight individual sand bodies although small in scale and limited in area, yet large in number, overlapping in plane and stacked vertically, make up a large-scale reservoir, which is favorable for large-scale accumulation of natural gas; the third is that the basin has gone through early-stage deep burial and latestage large-scale uplift (Fig. 11), with two accumulation ways volume flow charging and diffusion flow charging worked, raising gas accumulation efficiency significantly.

\subsection{Reservoir forming characteristics}

Large gas fields of low abundance were formed primarily in the intracontinental depression on a large-scale cratonic background. Gentle topography and inherited water 


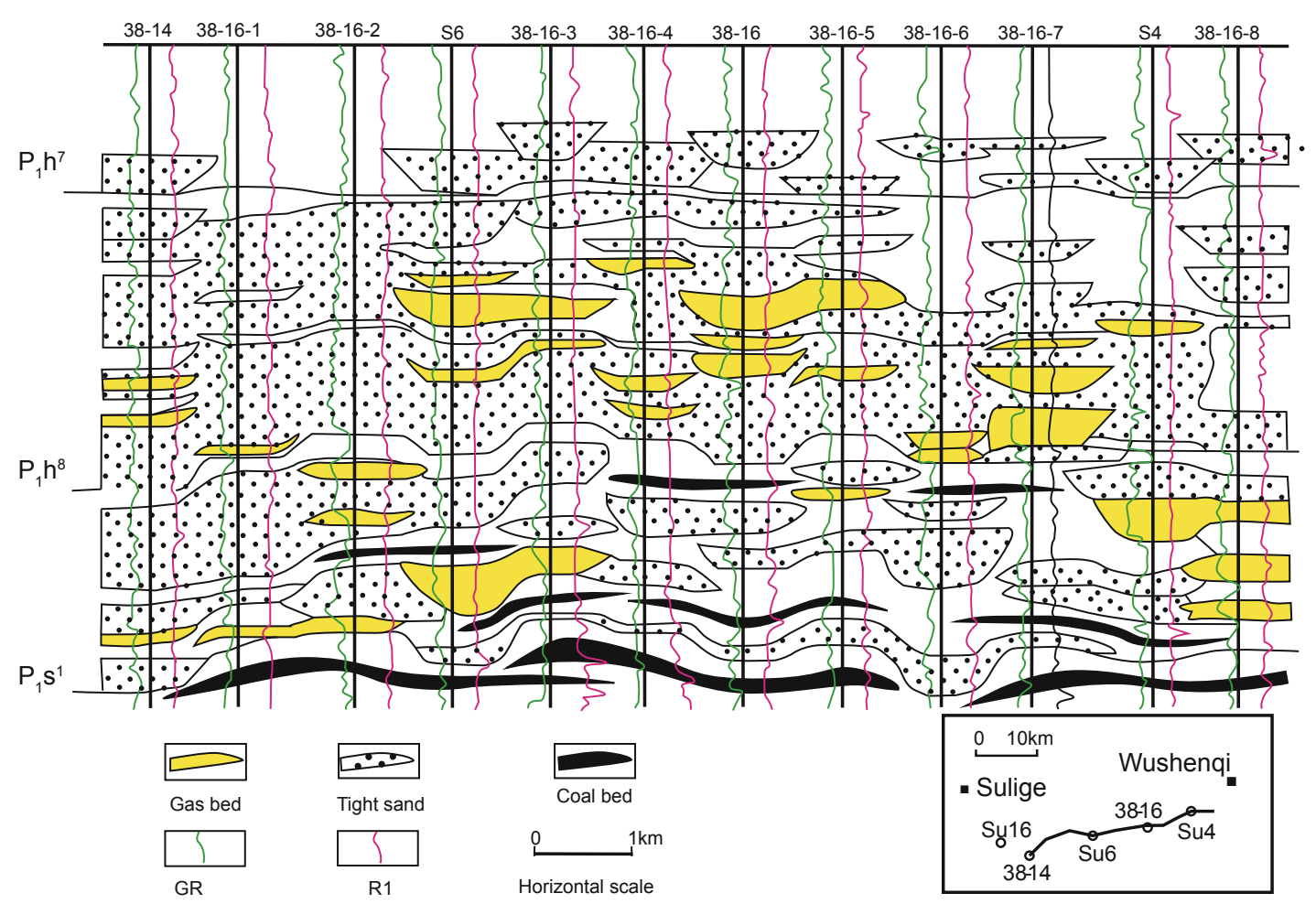

Fig. 9 Gas reservoir structure of the Sulige gas field, Ordos Basin

systems gave rise to a large area of sand bodies, which after constructive and destructive diagenesis formed a "reservoir body group" (Zhao et al, 2013). Most of the reservoirs are low in porosity and permeability, with sweet points with relatively high porosity and permeability developed locally. Low porosity and permeability sandstone occupies around $75 \%$ and tight sandstone with the permeability of $1-0.1 \mathrm{mD}$ occupies about $62 \%$. Porosity varies from $5 \%$ to $13 \%$ with an average value of $8.5 \%$, and the mean pore throat diameter is about $0.1-0.5 \mu \mathrm{m}$, representing micro-pore throat texture. The extremely tight reservoirs with a permeability of less than $0.1 \mathrm{mD}$ make up $32 \%$, with an average porosity of $4 \%$ to $7 \%$, and a mean pore throat diameter of less than $0.1 \mu \mathrm{m}$, belonging to nano-scale pore throat texture. Conventional reservoirs with a permeability of above $1 \mathrm{mD}$ account for $25 \%$, with an average porosity of more than $13 \%$, and the mean pore throat diameter of usually more than $0.5 \mu \mathrm{m}$, belonging to large pore throat texture. Large-scale reservoir bodies formed under the gentle structural setting present strong variation in three-dimensional space in both physical properties and internal structure, which led to cluster development and the distribution of stratigraphic-lithologic traps. These traps include lithologic traps formed by original deposition, physical property traps formed by diagenesis, and stratigraphic traps formed by epigenesis between fracture-cavity bodies and surrounding rocks (Zou et al,

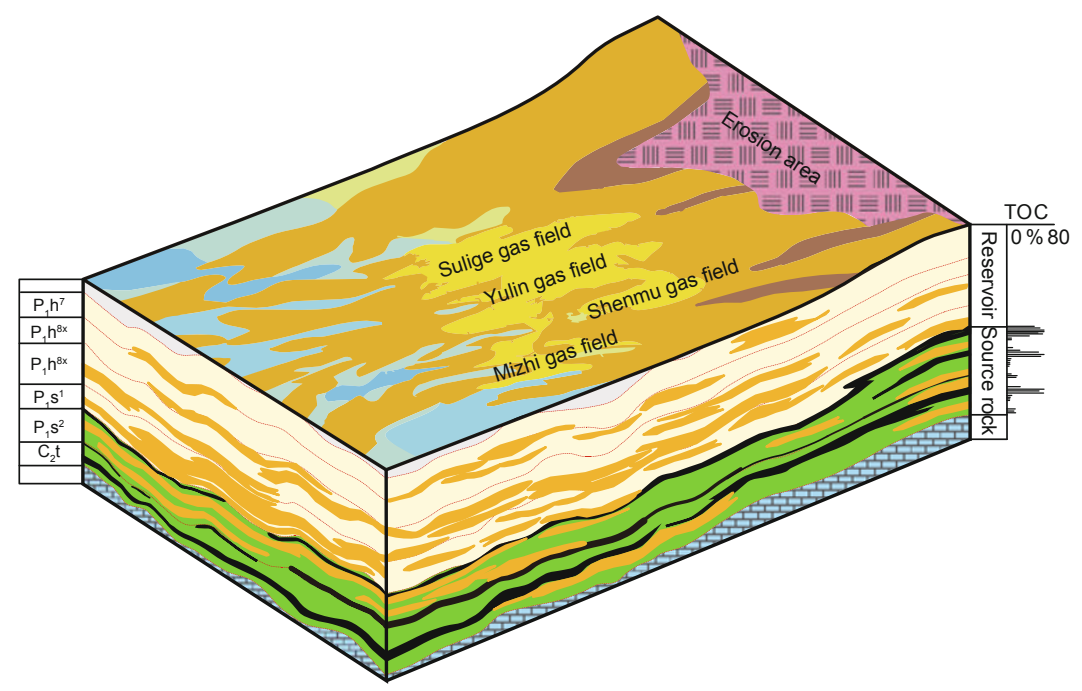

Fig. 10 The source-reservoir structural model in the Ordos Basin 


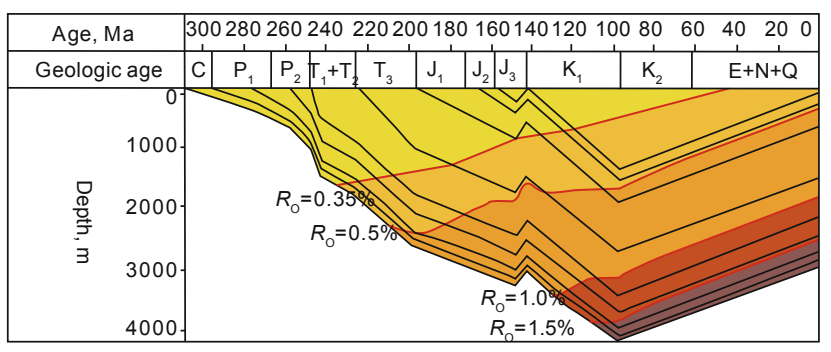

Fig. 11 Burial history of the Sulige gas field

2009). These independently-semi-independently distributed traps commonly appear in clusters, and a "gas reservoir group" would be formed in case of accumulation. Although individual reservoirs are limited in scale, the gas reservoir group consisting of thousands of reservoirs could be huge in scale, with the distribution area reaching up to several or tens of thousands of square kilometers, only the gas-bearing abundance is lower (Zhao et al, 2013).

Low abundance gas reservoirs are characterized by gasbearing in tight reservoirs and gas enrichment in sweet points. Sweet points have relatively high gas saturation, while widely distributed tight sandstones commonly bear gas as well. Statistics on porosity, permeability and gas saturation of tight sandstones and sweet points in 116 wells of the Sulige gas field reveal that the gas saturation of Upper Paleozoic sweet points is higher than that of tight sandstones. Sweet points in the member He- 8 have a gas saturation of $60 \%-70 \%$ with the average value of $59 \%$, and tight sandstone has lower gas saturation of $40 \%-50 \%$, with the average value of $46 \%$. The reservoir of the member Shan-1 is similar to the member He-8 in gas saturation, only slightly higher on the whole. Its average gas saturation of sweet points is $63 \%$, while that of tight sandstones is $46.04 \%$.

Higher in the north than the south, the gentle Upper Paleozoic structure in the Sulige gas field is a monocline with a dip of $1^{\circ}-3^{\circ}$ (Fu et al, 2008). Gas layers in the Sulige gas field are generally $5-15 \mathrm{~m}$ thick, individual gas-bearing sand bodies are commonly 1,000-2,500 $\mathrm{m}$ long and 100$250 \mathrm{~m}$ wide, and the maximum buoyancy generated by the gas column height is $0.15 \mathrm{MPa}$. Tight sandstone with low permeability as the direct caprock, provided sealing for the Sulige gas field. Its drainage pressure is greater than $1.2 \mathrm{MPa}$ in experimental tests, and therefore the drainage pressure difference between gas layer and caprock is greater than 0.5 $\mathrm{MPa}$. Therefore, the buoyancy generated by gas column is not high enough to break through the caprock so that gas reservoir can be preserved. Hence, large area gas accumulation could be formed within the whole basin, even without relatively thick gypsum acting as caprock like that in the Kela 2 highabundance large gas field (Fig. 12).

\subsection{Process and modes of reservoir accumulation}

\subsubsection{Volume flow charging during the burial stage}

Low abundance gas reservoirs are mainly tight reservoirs with low porosity and low permeability (Zou et al, 2009; Zhao et al, 2013). Affected by high expulsion pressure, natural gas generated by source rocks cannot charge the reservoir or migrate freely in the reservoir under buoyancy.

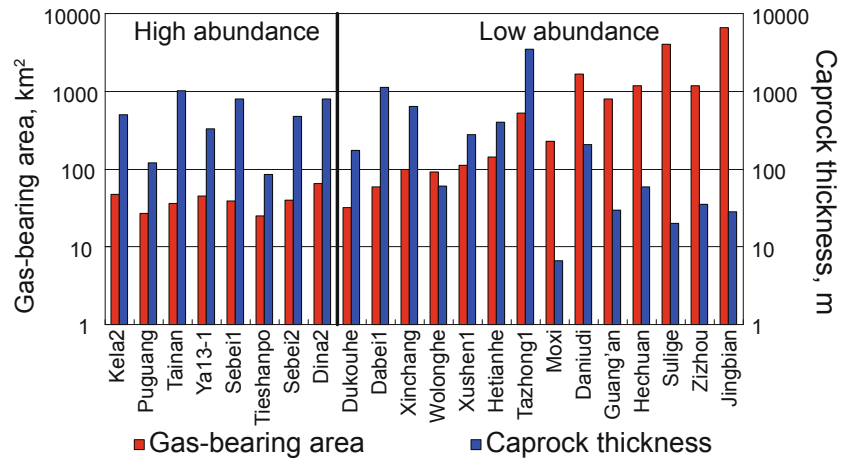

Fig. 12 Statistics on the gas-bearing area and direct caprock thickness of large gas fields in China

Actual tight reservoir core charging experiment reveals that natural gas must possess a certain start-up pressure to charge the reservoir and migrate within the reservoir $(\mathrm{Li}$ and Li, 2010). During the geological process, abnormally high pressure developed in source rocks is the necessary condition for natural gas charging tight reservoirs. In the case that overpressure of source rocks exceeds the displacement pressure of reservoir, natural gas is able to charge tight reservoirs and migrate within reservoirs in volume flow mode, which means the volume flow charging and migration driven by residual pressure difference is the primary natural gas charging mode during the highly efficient accumulation process of low abundance gas reservoirs in the strata burial stage.

Through quantitative diagenetic history research, the evolution of tight reservoir displacement pressure in geological history was detailed. Based on mercury injection data of 190 Upper Paleozoic samples from the Ordos Basin, the relationship between reservoir porosity and displacement pressure has been established. Reservoir displacement pressure has a good exponential relationship with porosity, and reservoir displacement pressure decreases exponentially with an increase in porosity. Thus the displacement pressure variation of natural gas charging reservoirs and migrating within reservoir in geologic stages can be estimated on the basis of porosity evolution research.

The critical condition of volume flow charging can be deduced by natural gas charging experiments on actual tight reservoir cores. Twelve sandstone samples with permeability of $(0.0043-1.37) \times 10^{-3} \mu \mathrm{m}^{2}$ were selected to conduct methane charging experiment under different pressure gradient conditions. The experiment reveals that a certain start-up pressure gradient must be available for the occurrence of volume flow in low porosity and low permeability core. The start-up pressure gradient varies exponentially with physical properties. When the permeability is $0.1 \times 10^{-3} \mu \mathrm{m}^{2}$, the minimum laboratory start-up pressure gradient is 0.1 $\mathrm{MPa} / \mathrm{cm}$, and the start-up pressure gradient under geological conditions is $5 \mathrm{MPa} / 100 \mathrm{~m}$ via similarity analysis. When the permeability reaches $1 \times 10^{-3} \mathrm{~mm}^{2}$, the minimum laboratory start-up pressure gradient decreases to $0.02 \mathrm{MPa} / \mathrm{cm}$, which equals to a subsurface pressure gradient of $0.25 \mathrm{MPa} / 100 \mathrm{~m}$.

The buoyancy gradient induced by gas-water density difference is $(0.023-4.9) \times 10^{3} \mathrm{~Pa} / \mathrm{m}$, which is much smaller than the start-up pressure gradient for volume flow in low 
porosity and low permeability reservoirs. Only when the residual formation pressure gradient exceeds the start-up pressure gradient, can volume flow charging and flowing under the strata conditions take place.

Fluid inclusion pressure testing and compaction analysis reveal the conditions for the occurrence of volume flow charging in geologic history in the Sulige gas field. There were multiple pressurization mechanisms in different stages of basin development, most of which occurred in the deep burial stage. Mudstones (in particular hydrocarbon source rocks) in depositional series are the primary layers for abnormal pressure development (Magara, 1978; Hunt, 1990), and sandstones are the main pressure relief layers, where a residual source-reservoir pressure difference pointing from source to reservoir is usually formed, which is the primary driving force for natural gas charging from source rock towards the reservoir.

Fluid inclusion pressure testing has also confirmed the existence of obvious overpressure in the deep burial stage of the Upper Paleozoic formations in the Ordos Basin. The maximum paleo-pressure coefficient of the Shanxi Formation reaches 1.4 , with the main frequency from 1.2 to 1.3 . The Shihezi Formation is dominated by normal pressure, with the maximum paleo-pressure coefficient of 1.1, and the main frequency ranges from 1.0 to 1.1. During the maximum buried depth stage of strata (Fig. 13), the residual pressure difference of at least 2-3 MPa occurred between the Shanxi Formation source rock and sand body with the occurrence of the source rock gas-generation peak. This residual pressure difference must lead to migration of natural gas generated by source rocks towards the reservoir driven by overpressure, i.e. overpressure charging (Fig. 13).

Based on the mudstone compaction curve (Liu and Wang, 2001), fluid inclusions were used to calculate the pressure calibration (Mi et al, 2004), and basin simulation techniques were utilized to outline the pressure evolution history of source rocks and reservoirs in the Sulige gas field. Source rocks and reservoirs are characterized by "high residual pressure and low residual pressure difference", i.e., source rocks and reservoirs have higher residual pressure, which is commonly greater than $15 \mathrm{MPa}$, whereas the residual sourcereservoir pressure difference is lower, which is commonly less than $3 \mathrm{MPa}$. The existence of residual source-reservoir pressure difference will lead to large scale volume flow charging of natural gas in the study area. Volume flow charging is the primary mode of natural gas charging in the deep burial stage.

\subsubsection{Diffusion flow charge in uplift stage}

Diffusion, a material transfer mode, often refers to a process in which a certain material transfers from a high concentration area to a low concentration area spontaneously along a concentration gradient eventually achieving concentration balance. Diffusion would occur as long as a concentration gradient exists (Lu et al, 2008; Korrani et al, 2012).

Previously, diffusion was commonly considered as one of the main factors causing damage to gas reservoirs. We had little idea about the contribution of diffusion to gas accumulation under specific conditions, and the
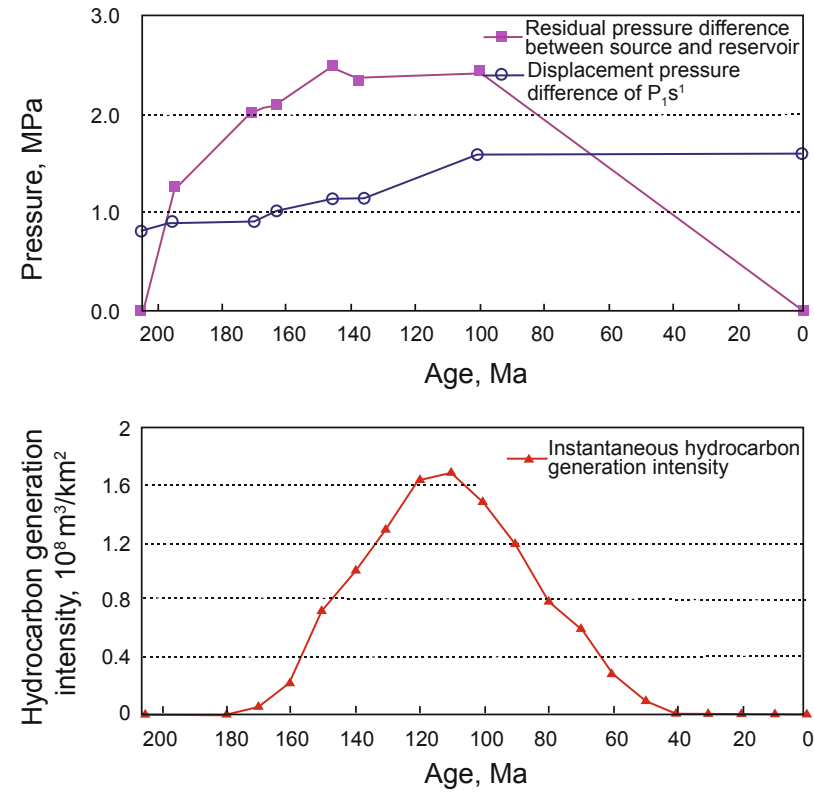

Fig. 13 Generation and evolution of residual source-reservoir pressure difference (upper) and hydrocarbon generation intensity of source rock (lower) in the Sulige gas field

understanding of the effect of diffusion charging to the largescale accumulation efficiency of medium-low abundance gas reservoirs, in particular, was insufficient (Nelson and Simmons, 1992; Zhang and Krooss, 2001; Schlomer and Krooss, 2004).

Highly efficient accumulation in the Sulige gas field primarily occurs where there is extensive contact between source rock and reservoir. During the accumulation natural gas underwent primary migration and short-distance vertical secondary migration, and insignificant lateral secondary migration (Wang et al, 1998; Li et al, 2008). This special accumulation condition made diffusion play a different role in large-scale accumulation of medium-low abundance gas reservoirs from that in conventional gas reservoir accumulation. In the burial stage of strata, when overpressure, in particular, developed in source rocks, the efficiency of volume flow charging is obviously greater than that of diffusion charging, and thus the contribution of diffusion charging is not obvious so that it is often ignored. However, volume flow charging tends to stop during the strata uplifting stage due to the decrease or disappearance of residual sourcereservoir pressure difference, but the diffusion charging condition still remains at this time, and diffusion becomes the main pathway for natural gas charging. The occurrence of large-scale accumulation in gas-bearing basins during the uplifting stage is a significant characteristic of highly efficient accumulation of low abundance gas reservoirs. Diffusion accumulation during the uplifting process is reflected in the following two aspects: one is that uplifting offloading leads to desorption and expansion of natural gas inside source kitchen, increasing the amount of free gas and providing a driving force for effective gas displacement; the other is that the uplifting process involved overall large-scale uplifting of sedimentary basin so that the hydrocarbon expulsion of the gas source kitchen could reach a large scale, therefore the accumulation range could be large. 
When large-scale uplifting and erosion happened, the overlying pressure of deep strata is reduced (i.e. offloading) and the temperature and pressure in strata drop (Hunt, 1995). The volume of gas absorbed in source rock pores may have greater expansion during the uplifting compared to the volume of rock framework (Jiang et al, 2004), which can become the significant driving force for gas discharging from source rock, leading to vast discharging of absorbed gas, increase of gas concentration around the source rock, providing the driving force for diffusion migration to reservoirs. Based on the gas state equation calculation, at the end of the Early Cretaceous the paleo-strata pressure of Permian Shihezi Formation in the Sulige gas field was about 48-53 $\mathrm{MPa}, 32-35 \mathrm{MPa}$ after temperature dropping, and is 29-30 MPa at present. Without considering natural gas loss or supplement, pressure reduction in the Sulige area due to temperature decrease can reach 30\%-35\%.

Based on geologic analysis of the Upper Paleozoic gas reservoirs in the Ordos Basin, a coupled diffusion-seepage model has been established, which is used in numerical simulation of volume flow charging and diffusion flow charging of Upper Paleozoic low abundance gas reservoirs in the Ordos Basin and diffusion and dissipation processes. Simulation results reveal that gas volume flow charging primarily occurred in the burial stage of basin, and the maximum volume flow charging rate reached $13 \times 10^{6} \mathrm{~m}^{3} /$ $\left(\mathrm{km}^{2} \cdot \mathrm{Ma}\right)$ in the maximum hydrocarbon generating stage in the Early Cretaceous. Natural gas diffusion flow charging mainly occurred in the uplifting stage of the basin, and the maximum charging rate was $18 \times 10^{6} \mathrm{~m}^{3} /\left(\mathrm{km}^{2} \cdot \mathrm{Ma}\right)$ (Fig. 14).

The overall basin simulation results reveal that the natural gas volume flow charging amount was about 180 trillion $\mathrm{m}^{3}$ and the diffusion flow charging amount was about 60 trillion $\mathrm{m}^{3}$ in the strata burial stage; whereas in the overall formation uplifting stage, the natural gas volume flow charging amount was less than 10 trillion $\mathrm{m}^{3}$ and the diffusion flow charging amount reached 70 trillion $\mathrm{m}^{3}$, which indicates that the primary mechanism for natural gas charging is diffusion flow charging in the strata uplifting stage. During the whole geologic history, the natural gas volume flow charging amount is 190 trillion $\mathrm{m}^{3}$ and the natural gas diffusion flow charging amount is 130 trillion $\mathrm{m}^{3}$, whereas the natural gas loss amount is 205 trillion $\mathrm{m}^{3}$ during this stage, and the

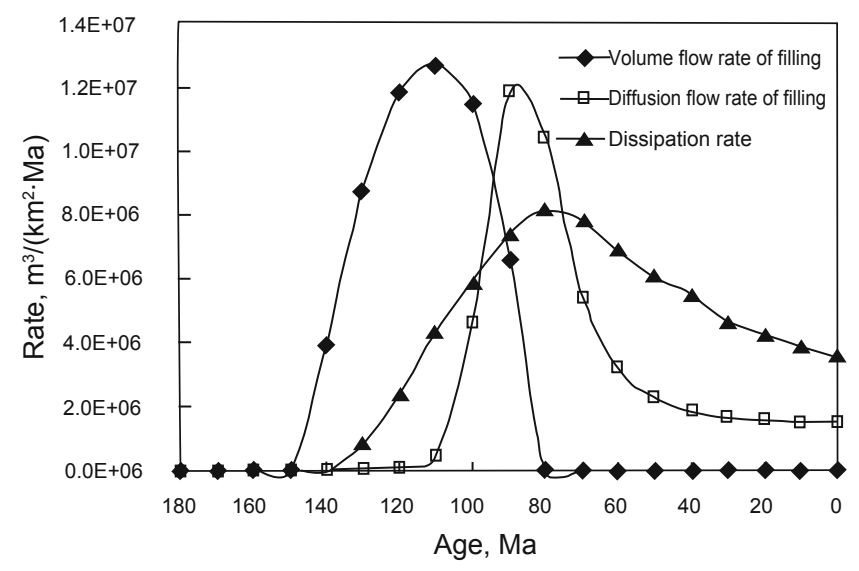

Fig. 14 Gas charging and dissipation rate evolution of Upper Paleozoic in Well Su-7, Sulige gas field volume flow charging amount is not sufficient enough to meet the diffusion loss of natural gas. Therefore, natural gas diffusion charging has made up for the diffusion loss of natural gas effectively, and made a positive contribution to highly efficient accumulation and preservation of large gas fields of low abundance.

\section{Conclusions}

1) Chinese large gas fields can be divided into two types: Type one, large gas fields with high abundance, are excellent in accumulation conditions, but limited in number and difficult to find; Type two are large gas fields with low abundance. The formation of the latter is an inevitable result of widely distributed continental facies basins in China. This type of field has poor reservoir physical properties and drastic changes in gas-bearing properties, but is large in scale once gas accumulation occurs. As the main part of Chinese natural gas resources, these large gas fields of low abundance can be effectively developed with the advancement of technologies. Despite difficulties in exploration and development, this kind of low abundance gas field will be major targets in future exploration and development.

2) In the formation of Kela2 large gas field with high abundance, late-stage rapid subsidence is the key factor for highly efficient gas accumulation besides the common favorable conditions such as source, reservoir, caprock, migration, trap and preservation. On one hand, the source rock generated a large amount of gas cumulatively and went through a rapid gas-generating process in late-stage rapid burial, which led to a quite high accumulation efficiency; on the other hand, the great residual pressure difference generated between gas source kitchen and reservoir during the rapid gas generation process became a strong driving force for natural gas migration towards traps.

3) Large gas fields with low abundance represented by the Sulige gas field do not have good accumulation conditions such as reservoir, trap and caprock, however they still have the feature of highly efficient accumulation. Their accumulation is more complicated, involving volume flow charging in the burial stage and diffusion flow charging in the uplift stage, and the sufficient gas supply in these two forms and continuous charging enable gas accumulation in low porosity low permeability reservoir bodies on large scale.

4) Research into the highly efficient accumulation process of these two types of large gas fields is very useful for evaluation and potential analysis of natural gas resources, especially the formation of large gas fields with low abundance. Some areas previously regarded unfavorable for gas accumulation, such as structural lows, structural uplift areas, poor reservoir and caprock areas turn out to possess conditions advantageous for forming large gas fields. The resources potential in these regions has been significantly enhanced, and these regions have become a potential new domain for natural gas exploration.

\section{Acknowledgements}

This paper is sponsored by the National Key Basic Research Program of China (2007CB2095). 


\section{References}

Chen S P, Tang L J, Jin Z J, et al. Thrust and fold tectonics and the role of evaporites in deformation in the Western Kuqa Foreland of Tarim Basin, Northwest China. Marine and Petroleum Geology. 2004. 21(8): 1027-1042

Dai J X. Major advancement of coal-formed gas exploration in the last 30 years in China. Petroleum Exploration and Development. 2009. 36(3): 264-279 (in Chinese)

Dai J X. Strengthen the natural gas geology research and explore more large gas fields. Natural Gas Geoscience. 2003. 14(1): 1-14 (in Chinese)

Dai J X, Huang S P, Liu Y, et al. Major advancement of natural gas exploration \& development in the last 60 years in China. Oil and Gas Geology. 2010. 31(6): 689-698 (in Chinese)

Fu J H, Wei X S and Ren J F. Distribution and genesis of large-scale Upper Palaeozoic lithologic gas reservoirs on Yi-Shan Slope. Petroleum Exploration and Development. 2008. 35(6): 664-667, 691 (in Chinese)

Hunt J M. Generation and migration of petroleum from abnormally pressured fluid compartments. AAPG Bulletin. 1990. 74(1): 1-12

Hunt J M. Petroleum Geochemistry and Geology (2nd Edition). New York: Freeman. 1995. 296-298

Jiang Z X, Pang X Q, Jin Z J, et al. Relationship between pore variation of reservoir and rebounding of sandstone during uplift and its application to the Daqing Oilfield. Earth Science-Journal of China University of Geosciences. 2004. 29(4): 420-426 (in Chinese)

Korrani A K N, Gerami S, Ghotbi C, et al. Investigation on the importance of the diffusion process during lean gas injection into a simple synthetic depleted naturally fractured gas condensate reservoir. Petroleum Science and Technology. 2012. 30(7): 655-671

Law B E. Basin-centered gas systems. AAPG Bulletin. 2002. 86(11): 1891-1919

Li M C and Li J. "Dynamic trap": A main action of hydrocarbon charging to form accumulations in low permeability tight reservoir. Acta Petrolei Sinica. 2010. 31(5): 718-722 (in Chinese)

Li Z D, Hui K Y, Li L, et al. Analysis of characteristics of gas migration and reservoir-forming in the Upper Paleozoic of northern Ordos Basin. Journal of Mineralogy and Petrology. 2008. 28(3): 77-83 (in Chinese)

Liang D G, Zhang S C, Chen J P, et al. Organic geochemistry of oil and gas in the Kuqa Depression, Tarim Basin, NW China. Organic Geochemistry. 2003. 34(7): 873-888

Liu G D and Wang D Q. The characteristics of abnormal pressure in deep formations in Qikou Sag, Huanghua Depression, Bohai Bay Basin. Petroleum Exploration and Development. 2001. 28(3): 22-24 (in Chinese)

Liu G D, Sun M L, Lü Y F, et al. The effectiveness assessment of gas accumulation processes in Kuqa Depression, Tarim Basin, Northwest China. Science in China Series D: Earth Sciences. 2008. 51(Supp.II): 117-125

Lu M, Connell L D and Pan Z J. A model for the flow of gas mixtures in adsorption dominated dual-porosity reservoirs incorporating multi-component matrix diffusion-Part II numerical algorithm and application examples. Journal of Petroleum Science and Engineering. 2008. 62(3-4): 93-101

Magara K. Compaction and Fluid Migration. Amsterdam-Oxford-New York: Elsevier Scientific Press. 1978. 8-20

Mi J K, Xiao X M, Liu D H, et al. Determination of paleo-pressure for a natural gas pool formation based on PVT characteristics of fluid inclusions in reservoir rocks-A case study of Upper-Paleozoic deep basin gas trap of the Ordos Basin. Science in China Series D: Earth Sciences. 2004. 47(6): 507-513

Muggeridge A, Abacioglu Y, England W, et al. The rate of pressure dissipation from abnormally pressured compartments. AAPG Bulletin. 2005. 89(1): 61-80
Nelson J S and Simmons E C. The quantificaton of diffusive hydrocarbon losses through cap rocks of natural gas reservoirs-a reevaluation: Discussion. AAPG Bulletin. 1992. 76(11): 1839-1841

Qin S F, Dai J X and Liu X W. The controlling factors of oil and gas generation from coal in the Kuqa Depression of Tarim Basin, China. International Journal of Coal Geology. 2007. 70(1-3): 255-263

Schlomer S and Krooss B M. Molecular transport of methane, ethane and nitrogen and the influence of diffusion on the chemical and isotopic composition of natural gas accumulations. Geofluids. 2004. 4(1): 81-108

Shanley K W, Cluff R M and Robinson J W. Factors controlling prolific gas production from low-permeability sandstone reservoirs: Implications for resource assessment, prospect development, and risk analysis. AAPG Bulletin. 2004. 88(8): 1083-1121

Wang Z L, Chen H L, Wang F Y, et al. Migration of gas in Upper Palaeozoic Group, Middle Ordos Basin. Petroleum Exploration and Development. 1998. 25(6): 1-4 (in Chinese)

$\mathrm{Xu} \mathrm{H}$, Zhang J F, Jia C Z, et al. Influence of tectonic uplift-erosion on formation pressure. Petroleum Science. 2010. 7(4): 477-484

Zhang L P, Bai G P, Luo X R, et al. Diagenetic history of tight sandstones and gas entrapment in the Yulin Gas Field in the central area of the Ordos Basin, China. Marine and Petroleum Geology. 2009. 26(6): 974-989

Zhang S C and Zhu G Y. Natural gas origins of large and medium-scale gas fields in China sedimentary basins. Science in China Series D: Earth Sciences. 2008. 51(1): 1-13

Zhang T W and Krooss B M. Experimental investigation on the carbon isotope fractionation of methane during gas migration by diffusion through sedimentary rocks at elevated temperature and pressure. Geochimica et Cosmochimica Acta. 2001. 65(16): 2723-2742

Zhao W Z and Liu W H. Basic Research on Formation \& Distribution of High Effective Gas Reservoir and Economic Development of Condensate and Low Effective Gas Reservoir. Beijing: Science Press. 2008: 1-30 (in Chinese)

Zhao W Z, Hu S Y, Wang H J, et al. Large-scale accumulation and distribution of medium-low abundance hydrocarbon resources in China. Petroleum Exploration and Development. 2013. 40(1): 1-13 (in Chinese)

Zhao W Z, Wang H J, Shan J Z, et al. Analysis of highly efficient gas reservoiring process in Kuqa Depression. Oil \& Gas Geology. 2005b. 26(6): 703-710 (in Chinese)

Zhao W Z, Wang H J, Shan J Z, et al. Geological analysis and physical modeling of structural pumping in high effective formation of Kela 2 gas field. Science in China Series D: Earth Sciences. 2006. 49(10): 1070-1078 (in Chinese)

Zhao W Z, Wang Z C, Zhang S C, et al. Analysis on forming conditions of deep marine reservoirs and their concentration belts in superimposed basins in China. Chinese Science Bulletin. 2007. 52(S1): 12-27

Zhao W Z, Wang Z C, Zhu Y X, et al. Forming mechanism of lowefficiency gas reservoir in Sulige Gas Field of Ordos Basin. Acta Petrolei Sinica. 2005c. 26(5): 5-9 (in Chinese)

Zhao W Z, Wang Z Y, Wang Z C, et al. Concept, connotation and evaluation index of high effective gas source kitchen and its action to the formation of high effective gas pool. Acta Sedimentologica Sinica. 2005a. 23(4): 710-718 (in Chinese)

Zhao W Z, Zhang S C, Wang F Y, et al. Gas systems in the Kuche Depression of the Tarim Basin: Source rock distributions, generation kinetics and gas accumulation history. Organic Geochemistry. 2005d. 36(12): 1583-1601

Zou C N, Tao S Z, Zhang X X, et al. Geologic characteristics, controlling factors and hydrocarbon accumulation mechanisms of China's large gas povinces of low porosity and permeability. Science in China Series D: Earth Sciences. 2009. 52(8): 1068-1090

(Edited by Hao Jie) 